\title{
Evaluation of Quality of Life in Mothers of Children with Down Syndrome
}

\author{
Saeid Abbasi $^{1}$, Firoozeh Sajedi ${ }^{1 *}$, Sahel Hemmati ${ }^{1}$, Tahereh Najafi Fard ${ }^{1}$, Mohammad Javad Azadchehr ${ }^{1}$, Abolfazl Poursadoghi $^{1}$
}

1. Pediatric Neurorehabilitation Research Center, University of Social Welfare and Rehabilitation Sciences, Tehran, Iran.

dtation: Abbasi, S., Sajedi, F., Hemmati, S., Najafi Fard, T., Azadchehr, M. J., \& Poursadoghi. A. (2016). Evaluation of quality of life in mothers of children with Down syndrome. Journal of Practice in Clinical Psychology, 4(2), 81-88. http://dx.doi.org/10.15412/J.JPCP.06040202

: http://dx.doi.org/10.15412/J.JPCP.06040202

\section{Article info:}

Received: 02 Nov. 2015

Accepted: 01 Mar. 2016

\section{Keywords:}

Quality of life, Mothers, Children with down syndrome

\section{ABSTRACT}

Objective: This study aimed to evaluate the quality of life and related factors in mothers of children with Down syndrome.

Methods: The study method was correlation-survey (sectional). Sampling was based on the available population. The research population consisted of all mothers of children with Down syndrome referred to the Down Syndrome Center: out of them 70 mothers of children with Down syndrome were randomly selected for study sample. Research tools were the WHO "quality of life" questionnaire, as well as a demographic and background information questionnaire. Data were analyzed using SPSS-16 software and ANOVA, multiple regression analysis and t-test.

Results: The results showed a significant association of physical health and environmental health with the housing type $(\mathrm{P}<0.05)$. So that mothers living in private houses have higher physical and environmental health than those who live in rental houses. But, There were no significant relationship between the independent variables and the other subscales and total score of "quality of life" ( $\mathrm{P}>0.05)$.

Conclusion: People's negative attitude toward some disabilities and limitations, society's little information, inappropriate cultural, social, and economic conditions, and insufficient available resources can be the most important factors affecting the quality of life. It is recommended that the relevant organizations provide services and conditions for mothers of children with Down syndrome in order to improve their quality of life and health.

\section{Introduction}

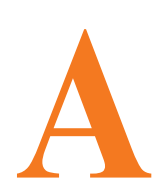

ccording to the definition of "quality of life" by WHO, life includes people's own perception of their position in life and in the cultural-value system in which they are living. Quality of life involves indicators such as good health, proper housing, employment, personal and family security, education and recreation, mental health, physical health, proper family life, proper social life, job security, and freedom (Sadeghi, Alipour, Abedi, \& Ghasmi, 2013). Quality of life is a broad concept that includes notions such as physical health, psychological state, level of independence, quality of social relationships (Bayatiani, Pourmohammadreza Tajrishi, Gangalivand, Mirzamani, \& Salehi, 2011) and relation to important en-

\footnotetext{
* Corresponding Author:

Firoozeh Sajedi, MD

Address: Pediatric Neurorehabilitation Research Center, University of Social Welfare and Rehabilitation Sciences, Tehran, Iran

Tel: +98 (912) 2266233

E-mail:fisajedi@gmail.com
} 
vironmental aspects. Environmental factors not only affect people's social cooperation, but also their quality of life and this is far more important in mentally disabled people than the general population (Glanz et al., 2010).

In systemic approach, family is considered a general system and the function of each of the family members affects the whole family system. The presence of a psychological disorder can eventually affect the whole system. Simultaneously, it can affect the quality of life dimensions such as the parents-children relationship, relationship with peers, career relationships, personal transition, and environmental structure (Ahmadi, Khankeh, Rahgozar, Teymouri, \& Sheikhona, 2013). One of the most common congenital abnormalities is Down syndrome (Abbasi, Sajedi, Hemmati, \& Rezasoltani, 2014; Truitt, Biesecker, Capone, Bailey, \& Erby, 2012).

Children with Down syndrome have special needs that challenge parents to prepare the best for their future. These children can have profound effects on families (Ravindranadan \& Raju, 2008). Parents of children with developmental disorders experience high levels of stress, health problems, loss of feeling responsible and defect in physical functions, and fatigue or burnout. Levels of impairment in "quality of life" for these families depend on children's chronic conditions and also economic, social, and community support conditions, child's characteristics, parents' personalities, and their coping strategies (Mugno, Ruta, D’Arrigo, \& Mazzone, 2007).

In research studies that have been widely conducted in different countries on different races and cultures, some issues have been studied such as parental stress, different conflicts, depression, especially in the first months after child's birth, marital conflict and divorce, and a variety of behavioral disorders (Cunningham, 1996; Hemmati, Asadi, \& Mirsepasi, 2005). Parents of children with Down syndrome are encountered with a lot of problems and stress due to their children (Amirmajd \& Sareskanrud, 2012).

Among the most important issues of this disease is the burden imposed on their families. Their medical problems, including cardiovascular problems, respiratory, nervous, endocrine, gastrointestinal, surgical, orthopedic, eye and blood safety, and even multiple admissions impose a lot of costs to the family (Evans \& Gray, 2000). Also, their maintenance and training, particularly with respect to their behavioral problems and low IQ will require additional costs and activities. According to studies, financial and social problems in tolerance and adaptation to new roles and responsibilities of parents are important (Hemmati, Asadi, \& Mirsepasi, 2005).
Mother's natural function, as the first person who communicates directly with the child, weakens when faced with a disabled child due to the growing problems and conditions, stereotypes, language problems, disorders, and lack of self-care skills and movement problems (Kermanshahi \& Sajedi, 2012). This condition is worse in third world countries, where families have limited resources and parents, especially mothers are unable to adequately address other aspects of life. Additionally, parents of children with disability are exposed to a lot of stressful factors for a long time that puts them in an inconvenient and inefficient conditions, leading to problems in their marital relationships, career, and relationships of parents with other children and finally can have negative consequences for children (Jalili et al., 2013)

These mothers show high levels of stress (Paster, Brandwein, \& Walsh, 2009), mental health problems, depression, anxiety, financial difficulties, negative emotions, self-blame, fear of child's future problems (Zani, Merino, \& Marcon, 2013), impaired physical performance, and fatigue or exhaustion.

The specific role of the mother for the pregnancy and birth, child care, and education makes them experience more pressure. Therefore, they need more support (Raina et al., 2005; Yilmaz, Erkin, \& İzki, 2013). Many studies have examined the quality of life of different groups in Iran, but a few of them focused on the quality of life of working mothers with children with Down syndrome. Abdul Hadi et al. (Haimour \& Abu-Hawwash, 2012) in a study assessed quality of life of parents with children with disability. They showed that there are significant differences in quality of life of parents with children with disability.

These differences depend on the type of disability and lack of interest of the child to the parents. Jalili et al. (Jalili et al., 2013) in a study evaluated the quality of life of mothers of children with severe cerebral palsy and factors affecting it. The results showed that the quality of life of mothers of children with cerebral palsy is moderate. Yaghmaei and Mohajeri (2013) in a qualitative study examined the quality of life of mothers of children with special needs (Yaghmaei \& Mohajeri, 2013). They showed that mothers of children with special needs have a low quality of life. Hagh Ranjbar et al. (Hagh Ranjbar, Kakavand, Borjali, \& Barmas, 2011) in a research evaluated the resiliency and quality of life of mothers of children with intellectual disability. The results showed that there is a positive and significant correlation between resiliency and quality of life. 
Davis et al. (2010) carried out another study in Melbourne, Australia, about the impact of the care for children with cerebral palsy on the quality of life of the primary caregiver (the mother) (Davis et al., 2010). The results showed that most of the challenges that mothers are faced with include the risk of losing physical, mental, and social well-being; the time limit for dealing with family issues and financial burden; and the lack of appropriate recreational programs. McConkey, TruesdaleKennedy, Chang, Jarrah, and Shukri (2008) also studied the effect of the mentally retarded children on their mothers (McConkey, Truesdale-Kennedy, Chang, Jarrah, \& Shukri, 2008). They concluded that mothers with mentally retarded kids have poor mental health as well as low family functioning and some level of stress that causes the behavioral problems of their children.

Because mothers' health is the infrastructure of families and communities, their problems also affect the physical and psychological health and family life satisfaction. The effects of their consent on the child's effective rehabilitation are undeniable. In recent years, besides considering the situation of children with disabilities, the quality of lives of their parents is considered. Thus, given the high prevalence of Down syndrome and disabilities resulting from it and its long-term effects on family members, especially mothers as the primary caregiver of the child, we aimed to investigate the quality of life and related factors in mothers of children with Down syndrome.

\section{Methods}

The present research method was descriptive-analytic. The population of the study was all mothers of the children with Down syndrome referred to Iran Center of Down Syndrome in Tehran, Iran. Sampling was based on the available population who wished to participate in the study. Inclusion criteria consisted of minimum education level at guidance school and married mothers living with their spouse. Exclusion criteria consisted of having severe mental disorders or using psychotropic drugs, or having another child with chronic illness. Finally, a total of 70 mothers of children with Down syndrome were included in the study. Next, the mothers were explained the objectives of the study and then, the "quality of life" and demographic questionnaires were distributed among them. The research was started after receiving official permission from University of Social Welfare and Rehabilitation Sciences and coordinating with the manager of Down Syndrome Society of Iran. The questionnaires were distributed among the mothers of children with Down syndrome. After the objective of the study was explained for them, they filled in the ques- tionnaire carefully and completely. The subjects were assured that they can quit the study whenever they want.

The confidentiality of personal information and findings was also explained to them. Seventy mothers attending the Down Syndrome Association were selected as the sample and "quality of life" and demographic questionnaires were distributed among them. The data were analyzed by SPSS ver 16. Descriptive statistics tests (mean, percentage, and standard deviation) and inferential statistics (t-test, Kolmogorov-Smirnov test, ANOVA, and multiple regression analysis) were performed for data analysis.

The research tool was the brief form of "quality of life" questionnaire, which is created by merging some areas and removal of a number of questions of WHO issued "quality of life" questionnaire. It consisted of 26 questions: The first 2 questions do not belong to any categories and assess public health and quality of life in general. In each area, 4-20 points will be achieved for the area, in which 4 shows the worst and 20 marks the best possible field status. These points can be converted to a range of 0 to 100 . In total, these questions include 4 areas of physical health, psychological health, social relations, and the environment.

This questionnaire has been administered and normalized in Iran by Nejat et al. (2006). Based on the results of the norm issue, Iranian psychometric properties of the questionnaire are valid and the instrument can be used in Iran. The questionnaire's test-retest interclass correlation index within 2 weeks was in the range of $75 \%$ to $84 \%$. The Cronbach $\alpha$ and values of validity also showed an acceptable validity of the test for Iranian populations as follows: Physical health, 77\%; Mental health, 77\%; Social relations, 75\%; and environmental health, 84\% (Nejat, Montazeri, Holakouie Naieni, Mohammad, \& Majdzadeh, 2006). Demographic questionnaire of the study evaluated age, education, occupation, economic status, and condition of housing.

\section{Results}

In the present study, 70 mothers of children with Down syndrome with an average age of $36.74 \pm 7.5$ years were studied. Table 1 presents demographic data of the mothers. As it can be seen in Table 1, nearly half of the mothers had secondary education and over $60 \%$ were housewives. The family income of $65 \%$ of the mothers in the study were less than 13000000 Iranian Rails and over $55 \%$ were living in rented houses.

Table 2 presents the mean and standard deviation of the variables of "quality of life" of mothers. This table shows 
Table 1. Demographic characteristics of mothers of children with Down syndrome.

\begin{tabular}{|c|c|c|c|c|c|}
\hline Demographic factors & $\mathbf{N}$ & percent & Demographic factors & $\mathbf{N}$ & Percent \\
\hline Family size & \multicolumn{5}{|c|}{ Job } \\
\hline 1 Child & 19 & 27.1 & Housekeeper & 44 & 62.9 \\
\hline 2 Children & 28 & 40 & Employed & 9 & 12.9 \\
\hline More than 2 children & 23 & 32.9 & Government Jobs & 17 & 24.3 \\
\hline Level of education & \multicolumn{5}{|c|}{ Family income } \\
\hline $\begin{array}{l}\text { Less than diploma } \\
\text { diploma }\end{array}$ & 33 & $\begin{array}{l}24.3 \\
47.1\end{array}$ & Less than $13,000,000$ Rails & 46 & 65.7 \\
\hline Bachelor's degree or higher & 20 & 28.6 & 13000000-20000000 Rails & 15 & 21.4 \\
\hline Housing & & & More than 25000000 Rails & 9 & 12.9 \\
\hline Personal & 29 & 41.4 & & & \\
\hline Rental & 41 & 58.6 & & & \\
\hline
\end{tabular}

PRACTIEE in PSYCH LOGY

Table 2. Descriptive characteristics of quality of life (with its subscales) of mothers of children with Down syndrome.

\begin{tabular}{ccc}
\hline Variable & Mean & SD \\
\hline Physical health & 13.9 & 2.24 \\
\hline Mental health & 10.94 & 2.48 \\
\hline Social relationships & 11.61 & 2.66 \\
\hline Environment health & 10.66 & 2.26 \\
\hline Total & 46.30 & 7.67 \\
\hline
\end{tabular}

PRACTICE in CLINICAL PSYCH LOGY

that environmental health had the least mean score of "quality of life" in this study and mental health ranks next with a minor difference. Using Kolmogorov-Smirnov test, we concluded that the distribution of "quality of life" is normal in each demographic variable $(\mathrm{P}>0.05)$, so to test these hypotheses, parametric methods were used. To compare means of each aspect of "quality of life" among demographic variables (number of children, education level, occupation and family income) and the type of housing, ANOVA and t test were used respectively. The results are shown in Tables 3 and 4.

As it can be seen in Table 3, environmental health mean value had a significant difference between the population size $(\mathrm{P}<0.05)$. Tukey test showed that this difference is due to significant difference between means of families with one child, families with 2 children and more than 2 children. The environmental health mean also had a significant difference $(\mathrm{P}<0.05)$ between mother's level of education, but this difference was due to a significant difference between the mean of education before and after diploma.
Table 4 shows that the averages of physical health and environmental health have significant differences regarding the subjects' types of housing $(\mathrm{P}<0.05)$. To evaluate the prediction of variables like family size, education level, occupation, income, and housing type in the "quality of life" of mothers of children with Down syndrome, multiple regression analysis was used. Because, our goal was to find predictive variables, we entered all variables in this analysis simultaneously and used multiple regression method.

\section{Discussion}

Quality of life is affected by factors such as beliefs, attitudes; as well as cultural, economic, social, and religious values. The present study aimed to evaluate the quality of life of mothers of children with Down syndrome and its related factors. The results showed that the quality of life among mothers of children with Down syndrome is not in a desirable condition. 
Table 3. Results of ANOVA for comparing means of each dimension of "quality of life" among family size, education level, occupation and family income of mothers of children with Down syndrome.

\begin{tabular}{|c|c|c|c|c|c|c|c|c|c|c|c|}
\hline \multicolumn{2}{|c|}{$\begin{array}{c}\text { Quality of life } \\
\text { variables }\end{array}$} & \multicolumn{2}{|c|}{ Physical health } & \multicolumn{2}{|c|}{ Mental health } & \multicolumn{2}{|c|}{$\begin{array}{l}\text { Social relation- } \\
\text { ships }\end{array}$} & \multicolumn{2}{|c|}{$\begin{array}{l}\text { Environment } \\
\text { health }\end{array}$} & \multicolumn{2}{|c|}{ Total } \\
\hline & & $\begin{array}{l}\text { Mean } \\
\text { (SD) }\end{array}$ & $f$ & $\begin{array}{l}\text { Mean } \\
\text { (SD) }\end{array}$ & $f$ & $\begin{array}{c}\text { Mean } \\
\text { (SD) }\end{array}$ & $f$ & $\begin{array}{l}\text { Mean } \\
\text { (SD) }\end{array}$ & $f$ & $\begin{array}{l}\text { Mean } \\
\text { (SD) }\end{array}$ & $f$ \\
\hline \multirow{6}{*}{ Family siza } & 1 child & 13.05 & & 11.00 & & 11.32 & & 9.32 & & 44.48 & \\
\hline & & (1.75) & & $(2.21)$ & & (1.83) & & (1.33) & & (5.65) & \\
\hline & 2 child & 13.25 & 0.142 & 11.11 & 0.176 & 11.46 & 0.456 & 11.11 & $5.176^{*}$ & 46.93 & 0.573 \\
\hline & & (2.33) & $(0.868)$ & (2.33) & $(0.839)$ & $(3.20)$ & $(0.636)$ & (2.44) & $(0.008)$ & (8.41) & $(0.567)$ \\
\hline & $\begin{array}{l}\text { More than } 2 \\
\text { child }\end{array}$ & 12.91 & & 10.70 & & 12.04 & & 11.22 & & 46.87 & \\
\hline & & (2.56) & & $(2.93)$ & & $(2.57)$ & & $(2.25)$ & & (8.26) & \\
\hline \multirow{6}{*}{$\begin{array}{c}\text { Level of } \\
\text { education }\end{array}$} & $\begin{array}{l}\text { Less than } \\
\text { diploma }\end{array}$ & 13.76 & & 11.24 & & 12.53 & & 11.88 & & 49.41 & \\
\hline & & (2.77) & & $(2.61)$ & & $(2.48)$ & & $(2.42)$ & & (8.30) & \\
\hline & $\begin{array}{l}\text { Bachelor of } \\
\text { science }\end{array}$ & 12.70 & $\begin{array}{c}1.292 \\
(0.281)\end{array}$ & 10.73 & $\begin{array}{c}0.255 \\
(0.776)\end{array}$ & 10.91 & $\begin{array}{l}2.476 \\
(0.092)\end{array}$ & 10.15 & $\begin{array}{l}3.680^{*} \\
(0.030)\end{array}$ & 44.48 & $\begin{array}{c}2.445 \\
(0.094)\end{array}$ \\
\hline & & (2.23) & & $(2.61)$ & & (2.78) & & (2.33) & & (7.81) & \\
\hline & $\begin{array}{l}\text { More than } \\
\text { B. A }\end{array}$ & 13.15 & & 11.05 & & 12.00 & & 10.45 & & 46.65 & \\
\hline & & (1.66) & & (2.23) & & $(2.40)$ & & $(1.60)$ & & (6.17) & \\
\hline \multirow{6}{*}{ Job } & Housewife & 12.77 & & 10.57 & & 11.68 & & 10.59 & & 45.61 & \\
\hline & & (2.16) & & (2.16) & & (2.70) & & $(2.21)$ & & (7.05) & \\
\hline & $\begin{array}{c}\text { Self- } \\
\text { employed }\end{array}$ & 13.24 & $\begin{array}{l}1.905 \\
(0.157)\end{array}$ & 11.12 & $\begin{array}{l}2.267 \\
(0.111)\end{array}$ & 11.06 & $\begin{array}{c}0.707 \\
(0.497)\end{array}$ & 10.65 & $\begin{array}{l}0.120 \\
(0.887)\end{array}$ & 46.06 & $\begin{array}{c}0.277 \\
(0.277)\end{array}$ \\
\hline & & $(2.25)$ & & $(2.93)$ & & $(2.73)$ & & $(2.62)$ & & (8.73) & \\
\hline & $\begin{array}{c}\text { Government } \\
\text { job }\end{array}$ & 13.24 & & 12.44 & & 12.33 & & 11.00 & & 50.11 & \\
\hline & & $(2.25)$ & & (2.74) & & $(2.40)$ & & (1.93) & & $(8.22)$ & \\
\hline
\end{tabular}

Table 4. Results of t-test to compare means of each aspect of quality of life between housing types among mothers of children with Down syndrome.

\begin{tabular}{|c|c|c|c|c|c|c|c|c|c|c|}
\hline \multirow{2}{*}{$\begin{array}{c}\text { Quality of life } \\
\text { Variables }\end{array}$} & \multicolumn{2}{|c|}{ Physical health } & \multicolumn{2}{|c|}{ Mental health } & \multicolumn{2}{|c|}{ Social relationships } & \multicolumn{2}{|c|}{$\begin{array}{c}\text { Environment } \\
\text { health }\end{array}$} & \multicolumn{2}{|c|}{ Total } \\
\hline & $\begin{array}{c}\text { Mean } \\
\text { (SD) }\end{array}$ & $f$ & $\begin{array}{c}\text { Mean } \\
\text { (SD) }\end{array}$ & $f$ & $\begin{array}{c}\text { Mean } \\
\text { (SD) }\end{array}$ & f & $\begin{array}{c}\text { Mean } \\
\text { (SD) }\end{array}$ & f & $\begin{array}{c}\text { Mean } \\
\text { (SD) }\end{array}$ & f \\
\hline & 13.79 & \multirow{4}{*}{$\begin{array}{l}2.285^{*} \\
(0.025)\end{array}$} & 10.79 & \multirow{4}{*}{$\begin{array}{l}-0.422 \\
(0.675)\end{array}$} & 12.00 & \multirow{4}{*}{$\begin{array}{c}1.020 \\
(0.311)\end{array}$} & 11.69 & \multirow{4}{*}{$\begin{array}{l}3.335^{*} \\
(0.001)\end{array}$} & 48.28 & \multirow{4}{*}{$\begin{array}{c}1.845 \\
(0.069)\end{array}$} \\
\hline \multirow{3}{*}{ Housing } & $(2.27)$ & & $(2.57)$ & & (3.14) & & $(2.36)$ & & $(8.60)$ & \\
\hline & 12.59 & & 11.05 & & 11.34 & & 9.93 & & 44.90 & \\
\hline & (2.11) & & (2.45) & & $(2.26)$ & & (1.89) & & (6.69) & \\
\hline
\end{tabular}


Malhotra, Khan, and Bhatia (2013) in a study assessed the quality of life in parents of children with developmental disabilities and concluded that in all subscales of "quality of life", these parents are faced with restrictions (Malhotra, Khan, \& Bhatia, 2013). In a study (Oliveira \& Limongi, 2011) on parents and caregivers of children with Down syndrome, the same instrument was used, but they that mothers had good quality of life $(84 \%)$, and were satisfied with the mental health $(55 \%)$. The results are inconsistent with this research's findings. Amirmajd andSareskanrud (2012) also studied parents of children with Down syndrome and normal children, which showed no significant difference between the qualities of their lives.

In the present study, mothers gained the highest scores on the physical aspect. Khanjani, Hatamizade, Hoseinian, Rahgozar, and Arjmand (2010) studied the impact of training on taking care of children with cerebral palsy and concluded that the quality of life of caregivers in all subscales and total score of the two general physical and mental areas improved, and the highest score was gained by the physical aspect (Khanjani, Hatamizade, Hoseinian, Rahgozar, \& Arjmand, 2010). This finding is consistent with our results. The results of this study can be explained, however, in the sense that taking care of children with Down syndrome brings along fatigue, time consumption, and stress for the parents. However, research shows that parents of these children more easily get used to this condition, because children with Down syndrome have positive features and less behavioral problems than children with other disabilities (Amirmajd \& Sareskanrud, 2012; Oliveira \& Limongi, 2011).

Other findings showed that environmental health had the lowest mean score in "quality of life". This finding is consistent with Oliveira \& Limongi (2011) findings. Also, the mean of environmental health of the mothers had a significant difference with their education level. This means that the higher the education level, the better would be their quality of life. These findings are consistent with Amirmajd and Sareskanrud (2012) and Bumin, Günal and Tükel (2008). Khayatzadeh (2009) showed that among all aspects of the "quality of life" of mothers, there was only a significant difference in environmental health and mothers with severe disability had lower environmental health.

Also Barnett and Boyce (1995) showed that parents of children with Down syndrome spend more time on taking care and less time on social activities. To explain these results, we can say that the permanent presence of mothers in the center, long distances, high transportation costs for these children, the children's medical training, lack of funding for treatment, treatment from the organi- zations, lack of information and activity during the visiting hours can be among the factors that have a negative impact on the lives of mothers and cause low environmental health score.

Psychological health is the second component with the lowest score in this study after environmental health. This result is consistent with the findings of, Bumin, Günal and Tükel (2008), Amirmajd and Sareskanrud (2012). Roche, Arsmend, and Barrotte quoted by Afrooz, Faramarzi, Mahmoud and Mokhtar (2008) in their research suggested that parents of children with Down syndrome have higher stress and depression than normal parents. Taking care of a child requires lots of patience and dedication on the part of parents. Many parents think of the child's disability as a sign of their own failure. They look for the goals that they could not reach in their children. When parents fail to achieve these goals and become aware of the child's intellectual disability, they would face double mental pressure which affect their mental health (Malekpour, Farahani, Aghaei, \& Bahrami, 2006).

Loss of social relations is one of the problems that children with intellectual disability may cause for parents. Research has shown that children with intellectual disability cause stress and mental disintegration in the family and their parents have lower level of mood (Koohsali, Mirzamani, Karimlo, \& Mirzamani, 2008). Keller and Honig (2004) also showed that mothers with disabled children have fewer social activities (Keller \& Honig, 2004). These limitations may be due to the negative attitude toward certain diseases, little information of the society, cultural conditions, and specific situation of the children. Since the demographic variables in this study explained only $17 \%$ of the "quality of life" of mothers of children with Down syndrome, it seems that other variables could affect the "quality of life".

Our study had some limitations; The most important of which was the small sample size. It is suggested that further research with greater number of participants in both groups (mothers and fathers) be conducted. Also relevant agencies should provide services and conditions for mothers of children with Down syndrome to improve their quality of life and health status.

In eastern societies, with different cultures, attitudes, and attention on individuals' lives, environmental factors should be assessed along with other related factors. Providing more convenience to hold workshops and courses and augmenting educational parental self-esteem programs lead to social connection of these parents. The results of studying the quality of life in the caregivers 
can be used to evaluate the humane and financial costs caused by Down syndrome, the effects of the new programs and measures, psychophysical changes, and social functioning conditions of the caregivers. Also, the results of the present study can shift the attention of the authorities to some vital needs of the family of the patients with mental disorders and prevent unpleasant consequences of the disorder on other family members.

The study had some limitations the most important of which was the low sample size, it is suggested that researches with greater number in both groups (mothers and fathers) be conducted. Also relevant agencies should provide services and conditions for mothers of children with Down syndrome to improve the quality of life and health status.

\section{Acknowledgements}

Hereby, we gratefully thank Down Syndrome Society of Iran and all the mothers participating in the study.

\section{References}

Abbasi, S., Sajedi, F., Hemmati, S., \& Rezasoltani, P. (2014). The Effectiveness of Life Skills Training on Quality of Life in Mothers of Children with Down syndrome. Iranian Rehabilitation Journal, 12(22), 29-34.

Afrooz, G. A., Faramarzi, S., Mahmoud, M., \& Mokhtar, M. (2008). [The psychological impact of early interventions and family-centered mental health of mothers of children with Down syndrome (Persian)]. Journal of Psychology \& Education, $8(2), 1-24$.

Ahmadi, M., Khankeh, H. R., Rahgozar, M., Teymouri, R., Sheikhona, M. (2013). The Quality of Life in Caregivers of Acute and Chronic Patients with Schizophrenia. Journal of Practice in Clinical Psychology , 1(3), 183-186.

Amirmajd, M., \& Sareskanrud, K. K. (2012). A comporative study of life between parent of children with Down syndrome and parent normal children. Journal of Engineering and Applied Sciences, 2(3), 74-78.

Barnett, W. S., \& Boyce, G. C. (1995). Effects of children with Down syndrome on parents' activities. American Journal of Mental Retardation, 100(2), 115-127.

Bayatiani, A., Pourmohammadreza Tajrishi, M., Gangalivand, N., Mirzamani, M., \& Salehi, M. (2011). [The Relationship between Social Network and Quality of Life in Parents of students with Intellectual Disabilities (Persian)]. Iranian Journal of Exceptional Children, 2(11), 163-174.

Bumin, G., Günal, A., \& Tükel, Ş. (2008). Anxiety, depression and quality of life in mothers of disabled children. Medical Journal of Suleyman Demirel University, 15(1), 6-11.
Cunningham, C. (1996). Families of children with Down syndrome. Down Syndrome Research and Practice, 4(3), 87-95.

Davis, E., Shelly, A., Waters, E., Boyd, R., Cook, K., \& Davern, M. (2010). The impact of caring for a child with cerebral palsy: Quality of life for mothers and fathers. Child: Care, Health and Development, 36(1), 63-73.

Evans, D. W., \& Gray, F. L. (2000). Compulsive-like Behavior in Individuals with Down Syndrome: Its Relation to Mental Age Level, Adaptive and Maladaptive Behavior. Child Development, 71(2), 288-300.

Glanz, B. I., Healy, B. C., Rintell, D. J., Jaffin, S. K., Bakshi, R., \& Weiner, H. L. (2010). The association between cognitive impairment and quality of life in patients with early multiple sclerosis. Journal of the Neurological Sciences, 290(1), 75-79.

Hagh Ranjbar, F., Kakavand, A., Borjali, A., \& Barmas, H. (2011). [Resiliency and quality of life of mothers of children with mental retardation (Persian)]. Journal of Health Psychology, 1(1), 177-187.

Haimour, A. I., \& Abu-Hawwash, R. M. (2012). Evaluating Quality of Life of parents having a child with disability. International Interdisciplinary Journal of Education, 1(2), 37-43.

Hemmati, S., Asadi, A. A., \& Mirsepasi, Z. (2005). [Family problems, people with Down syndrome (Persian)]. Rehabilitation Journal, 6(3), 20-24.

Jalili, N., Goudarzi, M., Rsafyany, M., Haghgoo, H., Dalvand, H., \& Marjan, F. (2013). [Quality of life in mothers of children with severe cerebral palsy and factors affecting it (Persian)] Journal of Modern Rehabilitation, 7(3), 40-47.

Keller, D., \& Honig, A. S. (2004). Maternal and paternal stress in families with school-aged children with disabilities. American Journal of Orthopsychiatry, 74(3), 337-348.

Kermanshahi, S., \& Sajedi, F. (2012). [Protective effect of health promotion program on life quality of mothers of children with cerebral palsy (Persian)]. Journal of Rehabilitation, 13(2), 8-17.

Khanjani, M., Hatamizade, N., Hoseinian, M., Rahgozar, M., \& Arjmand, M. (2010). [Effects of training on how to care for children with cerebral palsy and their family caregivers' quality of life (Persian)]. Journal of Rehabilitation, 10(39), 38-42.

Khayatzadeh, M. (2009). [A comparative study about quality of life in mothers of children with cerebral palsy, mental retardation and mothers of normal children (Persian)]. Daneshvar, 17(83), 49-58

Koohsali, M., Mirzamani, M., Karimlo, M., \& Mirzamani, M. (2008). [Comparing of social adjustment in mothers of educable mentally retarded daughter (Persian)]. Journal of Behavioral Sciences, 2(2), 165-172.

Malekpour, M., Farahani, H., Aghaei, A., \& Bahrami, A. (2006). [The effect of life-skills training on mothers stress having mentally retarded and normal children (Persian)]. Research on Exceptional Children, 20(2), 661-676.

Malhotra, S., Khan, W., \& Bhatia, M. S. (2013). Family Environment as a Determinant of Quality of life of Mothers of children With intellectual Disability. Delhi Psychiatry Journal, 16(1), 149-154. 
McConkey, R., Truesdale-Kennedy, M., Chang, M. Y., Jarrah, S., \& Shukri, R. (2008). The impact on mothers of bringing up a child with intellectual disabilities: A cross-cultural study. International Journal of Nursing Studies, 45(1), 65-74.

Mugno, D., Ruta, L., D’Arrigo, V. G., \& Mazzone, L. (2007). Impairment of quality of life in parents of children and adolescents with pervasive developmental disorder. Health and Quality of Life Outcomes, 5(22), 1-9.

Nejat, S., Montazeri, A., Holakouie Naieni, K., Mohammad, K., \& Majdzadeh, S. R. (2006). [The World Health Organization quality of Life (WHOQOL-BREF) questionnaire: Translation and validation study of the Iranian version (Persian)]. Journal of School of Public Health and Institute of Public Health Research, $4(4), 1-12$.

Oliveira, E. D., \& Limongi, S. C. (2011). Quality of life of parents/ caregivers of children and adolescents with Down syndrome. Journal da Sociedade Brasileira de Fonoaudiologia, 23(4), 321-327.

Paster, A., Brandwein, D., \& Walsh, J. (2009). A comparison of coping strategies used by parents of children with disabilities and parents of children without disabilities. Research in Developmental Disabilities, 30(6), 1337-1342.

Raina, P., O'Donnell, M., Rosenbaum, P., Brehaut, J., Walter, S. D., \& Russell, D. (2005). The health and well-being of caregivers of children with cerebral palsy. Pediatrics, 115(6), e626e636.

Ravindranadan, V., \& Raju, S. (2008). Emotional intelligence and quality of life of parents of children with special needs. Indian: Journal of the Indian Academy of Applied Psychology, 34, 34-39.

Sadeghi, M., Alipour, A., Abedi, A., \& Ghasmi, N. (2013). [The Effect of Life Skills Training on the Life Quality of Adolescent Orphans (Persian)]. Social Welfare Quarterly, 13(49), 269-286.

Truitt, M., Biesecker, B., Capone, G., Bailey, T., \& Erby, L. (2012). The role of hope in adaptation to uncertainty: The experience of caregivers of children with Down syndrome. Patient Education and Counseling, 87(2), 233-238.

Yaghmaei, F., \& Mohajeri, S. (2013). [Quality of life of mothers of children with special needs: a qualitative study (Persian)] Journal of Nursing and Midwifery Uromieh, 11(12), 1033-1043.

Yilmaz, H., Erkin, G., \& İzki, A. A. (2013). Quality of Life in Mothers of children with cerebral palsy. ISRN Rehabilitation, 2013(6). doi: 10.1155/2013/914738

Zani, A. V., Merino, M. D., \& Marcon, S. S. (2013). The feelings and experience of a mother facing Down syndrome. Acta Scientiarum. Health Sciences, 35(1), 67-75. 